\title{
Acid-Catalyzed Oligomerization of Glycerol Investigated by Electrospray Ionization Mass Spectrometry
}

\author{
Miguel A. Medeiros, ${ }^{a}$ Maria H. Araujo, ${ }^{a}$ Rodinei Augusti, $*, a$ \\ Luiz C. A. de Oliveira ${ }^{b}$ and Rochel M. Lago ${ }^{a}$
}

\author{
${ }^{a}$ Departamento de Química, Instituto de Ciências Exatas, Universidade Federal de Minas Gerais, \\ 31270-901 Belo Horizonte-MG, Brazil
}

${ }^{b}$ Departamento de Química, Universidade Federal de Lavras, 37200-000 Lavras-MG, Brazil

\begin{abstract}
A oligomerização do glicerol catalisada por ácido foi investigada por espectrometria de massas com ionização electrospray, em modo de íon positivo, i.e. ESI(+)-MS. Os dados de ESI(+)-MS revelaram que a $280{ }^{\circ} \mathrm{C}$ e em meio ácido $(\mathrm{pH} 2)$, glicerol sofre sucessivas condensações intermoleculares para produzir espécieis oligoméricas, i.e. [(glicerol) $-(n-1) \mathrm{H}_{2} \mathrm{O}$ ] $(\mathrm{n}=2-5)$. Esses resultados de ESI(+)-MS, em associação com as informações obtidas por análises de infravermelho e RMN de ${ }^{1} \mathrm{H}$ e ${ }^{13} \mathrm{C}$, indicaram que esses oligômeros sofrem desidratações para formar uma mistura de produtos, composta principalmente por compostos cíclicos, assim como alquenos e derivados carbonílicos (aldeídos e cetonas).
\end{abstract}

Acid-catalyzed oligomerization of glycerol was investigated by direct infusion electrospray ionization mass spectrometry in the positive ion mode, i.e. ESI(+)-MS. The ESI(+)-MS data revealed that at $280^{\circ} \mathrm{C}$ and in acidic medium ( $\left.\mathrm{pH} 2\right)$, glycerol undergoes successive intermolecular condensations to produce oligomeric species, i.e. [(glycerol $\left.)_{n}-(\mathrm{n}-1) \mathrm{H}_{2} \mathrm{O}\right](\mathrm{n}=2-5)$. These $\mathrm{ESI}(+)-\mathrm{MS}$ data, in association with the information provided by IR, ${ }^{1} \mathrm{H}$ and ${ }^{13} \mathrm{C} \mathrm{NMR}$ analyses, indicated that these oligomers undergo intramolecular dehydrations to form miscellaneous products comprised mainly by cyclic compounds as well as alkenes and carbonylic derivatives (aldehydes and ketones).

Keywords: electrospray ionization, mass spectrometry, glycerol, oligomerization, monitoring

\section{Introduction}

Vegetable and animal oil trans-esterification (synthesis of biodiesel) has been widely studied in recent years. ${ }^{1-9}$ Glycerol is the most important byproduct of biodiesel and approximately 200 million liters per year are estimated to be produced only in Brazil by 2013. For this reason, the development of processes to convert glycerol into valuable chemicals is of considerable interest. ${ }^{10}$ The main processes usually employed to convert glycerol into different products have been pyrolysis, oxidation, and condensation/ etherification. Pyrolysis ${ }^{11-13}$ has been investigated as an alternative approach to produce hydrogen and synthesis gas. Catalytic oxidation by palladium and gold has been proposed as a convenient route to synthesize glyceric acid. ${ }^{14-17}$ However, self-condensation to produce oligomers

\footnotetext{
*e-mail: augusti@ufmg.br
}

and etherification with assorted alcohols have been the most investigated processes. ${ }^{18-24}$

Most of the oligomerizations have been carried out in the presence of acid catalysts, such as $\mathrm{H}_{2} \mathrm{SO}_{4}$, clay, and zeolites, or bases, e.g. $\mathrm{Ca}(\mathrm{OH})_{2}, \mathrm{NaOH}$, and $\mathrm{KOH}$. In general, high yields (14-47\%) of diglycerol, i.e. [(glycerol) $\left.-\mathrm{H}_{2} \mathrm{O}\right]$, and triglycerol, i.e. [(glycerol $)_{3}-2 \mathrm{H}_{2} \mathrm{O}$ ], have been reported. ${ }^{25}$

Electrospray ionization mass spectrometry (ESI-MS), because of its appealing features, has quickly becoming an alternative approach to be conveniently employed to monitor a great variety of reactions. ${ }^{26-42}$ ESI-MS allows simple, rapid and direct analysis of reaction mixtures without any need of pre-treatment, making possible simultaneous detection from small to large molecules. The chemical structures of reagents and products (even the transient ones) in condensed phase can be proposed based on the mass-to-charge ratios $(\mathrm{m} / \mathrm{z})$ and fragmentation profiles of the ionic species transferred to the gas phase. 
In this work, we have used direct infusion electrospray ionization mass (and tandem mass) spectrometry, in conjunction with IR and NMR spectroscopy, to accomplish an overview of the acid-catalyzed oligomerization of glycerol. The results revealed that the reaction mechanism is complex with the formation of an unexpectedly large variety of products.

\section{Experimental}

Ultrapure glycerol (272 mmol), $\mathrm{H}_{2} \mathrm{SO}_{4}(2.72 \mathrm{mmol})$, and distilled water $(3 \mathrm{~mL})$ were mixed in a $200 \mathrm{~mL}$ glass reactor connected to a condenser and a collector flask. The system was placed inside a ceramic furnace and heated with a slope of $30^{\circ} \mathrm{C} \mathrm{min}^{-1}$ up to $280{ }^{\circ} \mathrm{C}$. Aliquots were taken at intervals of $30 \mathrm{~min}$ and diluted 1000 times with $\mathrm{MeOH} / \mathrm{H}_{2} \mathrm{O} 1: 1$. The $\mathrm{pH}$ of the diluted samples were adjusted to 2 by dropping $\mathrm{H}_{2} \mathrm{SO}_{4} 0.1 \mathrm{~mol} \mathrm{~L}^{-1}$.

ESI-MS analyses were conducted in an MS instrument (Agilent Trap XCT, Santa Clara, CA) equipped with an electrospray source operating in the positive ion mode. The diluted aliquots were directly infused into the ESI source at a flow rate of $5 \mu \mathrm{L} \mathrm{min}^{-1}$ by a micro syringe. ESI source conditions were as follows: heated capillary temperature $150{ }^{\circ} \mathrm{C}$; sheath gas $\left(\mathrm{N}_{2}\right)$ flow rate $5 \mathrm{~L} \mathrm{~min}^{-1}$; spray voltage $4 \mathrm{kV}$; tube lens offset voltage $25 \mathrm{~V}$, capillary voltage $25 \mathrm{~V}$. The mass spectra were acquired in a $50-500 \mathrm{~m} / \mathrm{z}$ range and were obtained as an average of 50 scans, each one requiring $0.2 \mathrm{~s}$. For the MS/MS experiments, the precursor ions were isolated with an isolation width of $1 \mathrm{~m} / \mathrm{z}$ unit and fragmented via collision-induced dissociation (CID) with the target gas (helium). The relative collision energy was adjusted to yield product ions in quantifiable abundance.

The aliquots were also analyzed by FTIR (Fourier Transform Infrared Spectrometry), as liquid films using a Perkin Elmer model GX FT-IR instrument (Norwalk, CT, USA), and ${ }^{1} \mathrm{H}$ and ${ }^{13} \mathrm{C}$ NMR (Nuclear Magnetic Resonance), in $\mathrm{D}_{2} \mathrm{O}$ solution and recorded on a Bruker CXP-200 spectrometer (Billerica, MA, USA).

\section{Results and Discussion}

Typical ESI(+)-MS of the reaction aliquots taken at different times are shown in Figure 1. The presence of an intense ion of $m / z 93$ (protonated glycerol $=[\text { glycerol }+\mathrm{H}]^{+}$) is clearly noticeable indicating the subsistence of glycerol in the reaction medium even after $2 \mathrm{~h}$ reaction. Furthermore, other ions of $m / z 75\left(\text { glycerol }-\mathrm{H}_{2} \mathrm{O}+\mathrm{H}\right]^{+}$) and 57 ([glycerol $\left.2 \mathrm{H}_{2} \mathrm{O}+\mathrm{H}\right]^{+}$) are also detectable. These ions probably arises from in-source dehydrations of [glycerol $+\mathrm{H}]^{+}$as they are also distinguishable in the ESI(+)-MS (not shown) of an aqueous solution of pure glycerol at $\mathrm{pH} 2$.
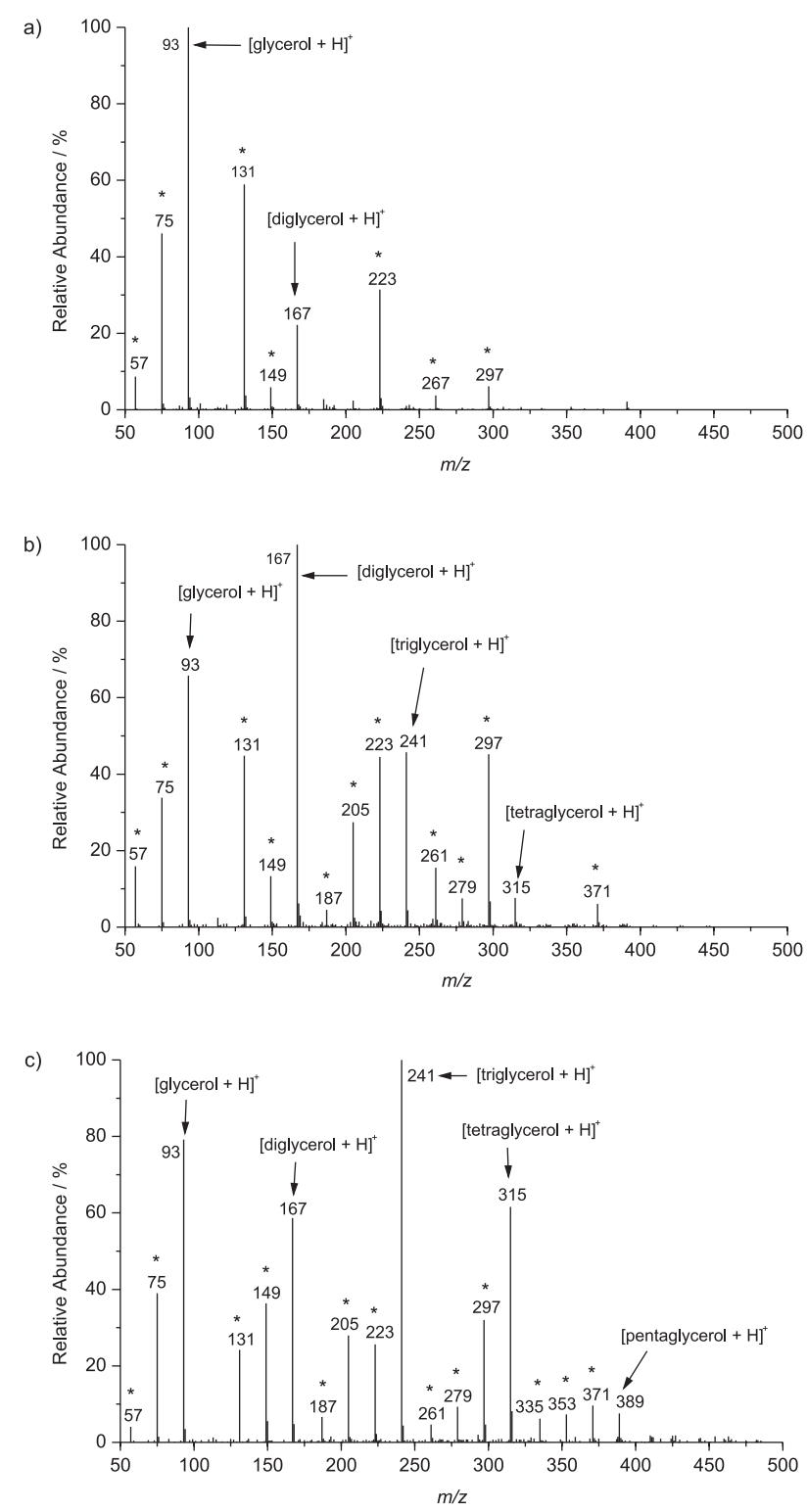

Figure 1. ESI(+)-MS of the acid-catalyzed oligomerization of glycerol conducted in aqueous medium at $280^{\circ} \mathrm{C}$. The aliquots were collected after reaction times of: (a) $30 \mathrm{~min}$; (b) $60 \mathrm{~min}$; (c) $120 \mathrm{~min}$. The ions marked with an asterisk (*) refer to dehydration products (see also Table 1 for a general overview of the products formed under these conditions).

A remarkable presence of an ion of $m / z, 167$ is also noticed in Figure 1. This corresponds to the protonated form of diglycerol, i.e. [( glycerol $\left.)_{2}-\mathrm{H}_{2} \mathrm{O}\right]$, formed under these reaction conditions via the condensation of two molecules of glycerol and loss of water. This condensation can occur via the primary or secondary hydroxyl groups at the glycerol molecule to yield linear ( $\alpha, \alpha$-diglycerol) and branched ( $\alpha, \beta$-diglycerol; $\beta, \beta$-diglycerol) isomers, as displayed in Scheme 1. 
<smiles>OCC(O)COCC(O)CO</smiles>

$\alpha, \alpha$-diglycerol<smiles>OCC(O)COC(CO)CO</smiles>

$\alpha, \beta$-diglycerol<smiles>OCC(CO)OC(CO)CO</smiles>

$\beta, \beta$-diglycerol

Scheme 1. Linear ( $\alpha, \alpha$-diglycerol) and branched ( $\alpha, \beta$-diglycerol, $\beta, \beta$-diglycerol) isomers of diglycerol.

As expected, the mass-selection and fragmentation of the ion of $m / z 167$ (Figure 2) yielded mainly product ions arising from losses of one or two molecules of water $(\mathrm{m} / \mathrm{z} 149$ and 131, respectively) besides to other product ions, such as [glycerol $+\mathrm{H}]^{+}(\mathrm{m} / z$, 93$)$, [glycerol $\left.-\mathrm{H}_{2} \mathrm{O}+\mathrm{H}\right]^{+}$ $\left(\mathrm{m} / \mathrm{z} \text { 75), and [glycerol }-2 \mathrm{H}_{2} \mathrm{O}+\mathrm{H}\right]^{+}(\mathrm{m} / \mathrm{z}$ 57). To illustrate the formation of such fragments, the dissociation pathways for protonated $\alpha, \alpha$-diglycerol are shown in Scheme 2.

In the ESI(+)-MS (Figure 1), the presence of ions of $m / z, 149$ and $m / z, 131$ is also promptly recognized. These ions are ascribed to be the protonated forms of products formed by successive dehydrations of diglycerol, namely [diglycerol $-\mathrm{H}_{2} \mathrm{O}$ ] and [diglycerol $-2 \mathrm{H}_{2} \mathrm{O}$ ], respectively (Table 1).

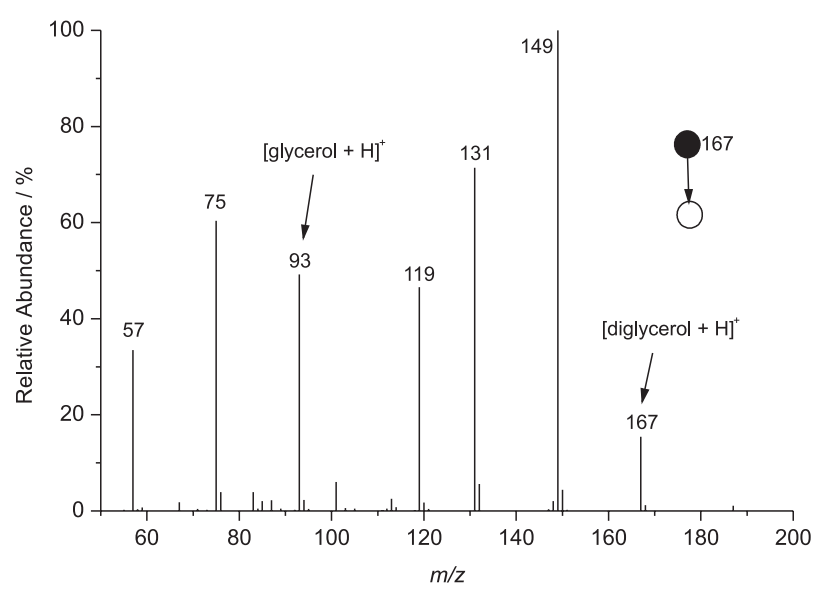

Figure 2. ESI(+)-MS/MS experiment with the ion of $m / z$ 167. For a complete interpretation of the fragmentation pathways of protonated $\alpha, \alpha$-diglycerol, see Scheme 2 .<smiles>C=C(C)O</smiles>

$m / z 57$<smiles>CCCCCCCCCCCO</smiles>

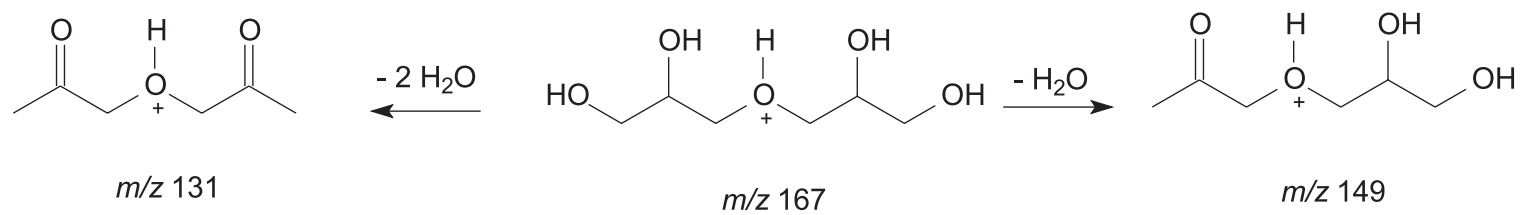<smiles>CC(=O)C(C)CCC(C)C</smiles><smiles>CC(=O)CO</smiles> 
Table 1. Primary products (diglycerol, triglycerol, tetraglycerol, and pentaglycerol) and their dehydration products formed upon acid-catalyzed oligomerization of glycerol at $280^{\circ} \mathrm{C}$. All these products were observed as their protonated forms in the ESI(+)-MS (Figure 1)

\begin{tabular}{ll}
\hline $\begin{array}{l}\text { Primary Oligomers } \\
(\mathrm{m} / z \text { of the protonated forms })\end{array}$ & $\begin{array}{l}\text { Dehydration Products } \\
(\mathrm{m} / z \text { of the protonated forms })\end{array}$ \\
\hline diglycerol (167) & $\begin{array}{l}\left.\text { [diglycerol }-\mathrm{H}_{2} \mathrm{O}\right](149) \\
{\left[\text { diglycerol }-2 \mathrm{H}_{2} \mathrm{O}\right](131)}\end{array}$ \\
triglycerol (241) & {$\left[\right.$ triglycerol $\left.-\mathrm{H}_{2} \mathrm{O}\right](223)$} \\
& {$\left[\right.$ triglycerol $\left.-2 \mathrm{H}_{2} \mathrm{O}\right](205)$} \\
& {$\left[\right.$ triglycerol $\left.-3 \mathrm{H}_{2} \mathrm{O}\right](187)$} \\
& {$\left[\right.$ tetraglycerol $\left.-\mathrm{H}_{2} \mathrm{O}\right](297)$} \\
& {$\left[\right.$ tetraglycerol $\left.-2 \mathrm{H}_{2} \mathrm{O}\right](279)$} \\
tetraglycerol (315) & {$\left[\right.$ tetraglycerol $\left.-3 \mathrm{H}_{2} \mathrm{O}\right](261)$} \\
& {$\left[\right.$ pentaglycerol $\left.-\mathrm{H}_{2} \mathrm{O}\right](371)$} \\
& {$\left[\right.$ pentaglycerol $\left.-2 \mathrm{H}_{2} \mathrm{O}\right](353)$} \\
pentaglycerol (389) & {$\left[\right.$ pentaglycerol $\left.-3 \mathrm{H}_{2} \mathrm{O}\right](335)$}
\end{tabular}

These findings thus indicate that under these experimental conditions (acidic medium and heating), diglycerol can easily lose one or two molecules of water to form a myriad of isomeric products. Scheme 3 shows, for instance, prototype products possibly formed as a result of the mono-dehydration of diglycerol, such as the cyclic species 1a-c (their formation have been reported by Barrault and coworkers ${ }^{18-24}$ that submitted glycerol to similar reaction conditions than those employed herein) besides the acyclic carbonyl compounds $\mathbf{2 a - b}$ and the alkene 2c. The presence of the last products in the reaction medium was evidenced by the data from IR and NMR spectra (not shown), which were acquired from an aliquot taken after a reaction time of $2 \mathrm{~h}$. Hence, an absorption band at $1725 \mathrm{~cm}^{-1}$, typically related to the $\mathrm{C}=\mathrm{O}$ stretching of aldehydes and ketones, was observed in the IR spectrum. The NMR records also revealed the presence of aldehydes (as evidenced by the signals at $9.6 \mathrm{ppm}$ in the ${ }^{1} \mathrm{H}$ NMR as well as 177 and $178 \mathrm{ppm}$ in the ${ }^{13} \mathrm{C}$ NMR) in addition to alkenes (owing to the existence of signals at $7.1 \mathrm{ppm}$ in the ${ }^{1} \mathrm{H}$ NMR as well as 100 and $166 \mathrm{ppm}$ in the ${ }^{13} \mathrm{C}$ NMR).

Note that all the products resulting from the monodehydration of diglycerol, including the ones shown in Scheme 3 (1a-c and 2a-c), possess the same chemical formula $\left(\mathrm{C}_{6} \mathrm{H}_{12} \mathrm{O}_{4}\right)$ and bear similar functional groups (especially hydroxyl substituents). Hence, as these protonated molecules are simultaneously selected inside the ion trap and dissociate in a quite similar way (yielding a number of fragments arising mainly from successive losses of water and other small molecules), the unambiguous characterization of a particular product based exclusively on such fragmentation profile is certainly unfeasible.

The ESI(+)-MS (Figure 1) reveals that besides diglycerol, heavier oligomers, comprising three, four, and five glycerol units, i. e. triglycerol ([(glycerol $\left.\left.)_{3}-2 \mathrm{H}_{2} \mathrm{O}\right]\right)$, tetraglycerol $\left(\left[(\text { glycerol })_{4}-3 \mathrm{H}_{2} \mathrm{O}\right]\right)$, and pentaglycerol ([(glycerol) $\left.\left.)_{5}-4 \mathrm{H}_{2} \mathrm{O}\right]\right)$, respectively (Table 1 and Scheme 4), were also formed.

As expected, the mass-selection and fragmentation of such protonated oligomers, of $\mathrm{m} / \mathrm{z} 241,315$, and 389, respectively, yielded product ions arising mainly from successive eliminations of water (Table 2). As previously stated, these products are likely comprised by a mixture<smiles>OCC1COC(CO)CO1</smiles>

$1 \mathrm{a}$<smiles>OCC1COCC(CO)O1</smiles>

$1 \mathrm{~b}$<smiles>O=CCCOCC(O)CO</smiles>

$2 b$

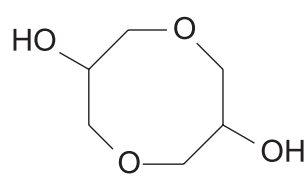

$1 \mathrm{c}$<smiles>C=C(CO)OC(CO)CO</smiles>

2c

Scheme 3. Examples of products possibly formed as a result of the mono-dehydration of diglycerol. 
<smiles>OCC(O)CO</smiles>

glycerol (92 Da)

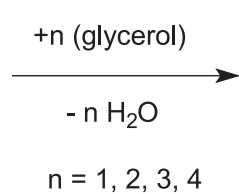<smiles>CC(CC(O)CO)OCC(C)(C)C(O)CO</smiles>

$$
\begin{gathered}
\mathrm{n}=1(\text { diglycerol; } 166 \mathrm{Da}) \\
\mathrm{n}=2(\text { triglycerol; } 240 \mathrm{Da}) \\
\mathrm{n}=3(\text { tetraglycerol; } 314 \mathrm{Da}) \\
\mathrm{n}=4(\text { pentaglycerol; } 388 \mathrm{Da})
\end{gathered}
$$

Scheme 4. Oligomeric products formed by the self-condensation of glycerol in aqueous acidic medium at $280^{\circ} \mathrm{C}$. Note that only the linear isomers, formed via condensations of the primary hydroxyl groups, are displayed herein.

of different isomers (linear and branched) that are formed depending on the nature of the $\mathrm{OH}$ group (primary or secondary) active in the condensation step.

Table 2. Major product ions arising from the collision-induced dissociation (CID) of protonated triglycerol $(\mathrm{m} / \mathrm{z}, 241)$ and tetraglycerol $(\mathrm{m} / \mathrm{z}, 315)$

\begin{tabular}{ll}
\hline Precursor ion $(\mathrm{m} / \mathrm{z})$ & Product ions (relative abundance / \%) \\
\hline${\text { [triglycerol }+\mathrm{H}]^{+}(241)}$ & $223(14), 205(3), 167(14), 149(37), 131$ \\
& $(24), 93(3), 75(5)$ \\
{$[\text { tetraglycerol }+\mathrm{H}]^{+}(315)$} & $297(10), 279(1), 241(13), 223(17), 205$ \\
& $(4), 167(18), 149(20), 131(16)$ \\
\hline
\end{tabular}

Similarly to that verified for diglycerol, the heavier oligomers, i.e. triglycerol, tetraglycerol, and pentaglycerol, promptly generate a number of dehydration products (possibly comprised by a mixture of cyclic and unsaturated acyclic compounds: alkenes, aldehydes, and ketones) under these experimental conditions. The protonated forms of such compounds are detected in the ESI(+)-MS (Figure 1) and a general overview of their chemical compositions is presented in Table 1.

In Figure 3, the fraction of the ions of $m / z$ 93, 167, 241, 315 , and 389 (protonated glycerol, diglycerol, triglycerol, tetraglycerol, and pentaglycerol, respectively), given as a quotient ratio between the absolute intensity of one of such ions and the sum of the absolute intensities of the whole set of ions, are plotted against the reaction time. This is certainly a convenient approach to monitor the changes in the relative concentrations of such species during the reaction course. Hence, the results show that after $2 \mathrm{~h}$ reaction more than $90 \%$ of glycerol is consumed. Furthermore, during the first 30 min a relatively high concentration of diglycerol is formed. At longer reaction times, however, its concentration decreases whereas the amount of the heavier oligomers (triglycerol, tetraglycerol, and pentaglycerol) concomitantly increases. These results, in association with the observed gradual rise in the medium viscosity (from $1000 \mathrm{cp}$ for pure glycerol to $5978 \mathrm{cp}$ for the raw material obtained after $2 \mathrm{~h}$ reaction), strongly support the assumption that glycerol is continuously converted into the heavier and more viscous oligomeric compounds.

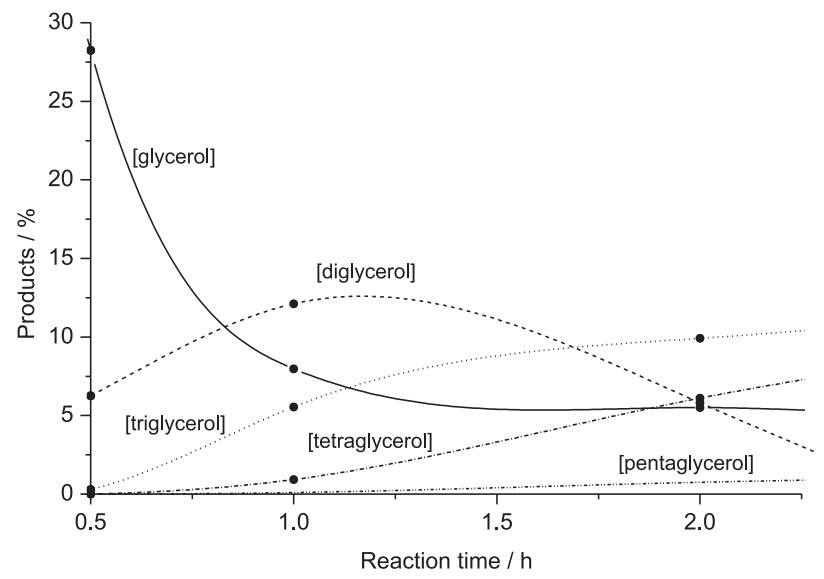

Figure 3. Fractions of the ions of $\mathrm{m} / \mathrm{z} 167$ (protonated diglycerol), 241 (protonated triglycerol), 315 (protonated tetraglycerol), and 389 (protonated pentaglycerol) as a function of reaction time. Each fraction was calculated as the quotient ratio between the absolute intensity of one of such ions and the sum of the absolute intensities of the whole set of ions.

In Figure 4 the fraction of protonated diglycerol (of $\mathrm{m} / \mathrm{z} 167$ ) and its dehydration products (of $\mathrm{m} / \mathrm{z}, 149$ and 131) are plotted against the reaction time. Curiously, the results show that diglycerol only becomes predominant after a reaction time of 30 minutes. Before this time, the fully dehydrated compound, [diglycerol $-2 \mathrm{H}_{2} \mathrm{O}$ ], is found to be the major product. Similar trend was observed for triglycerol and its dehydration products (not shown). These findings probably indicate that at the beginning of the reaction process, diglycerol and triglycerol are quickly converted into their dehydration products. At longer reaction times, however, the increasingly amount of water in the reaction medium allows the reconstitution of the initial condensation adducts. 


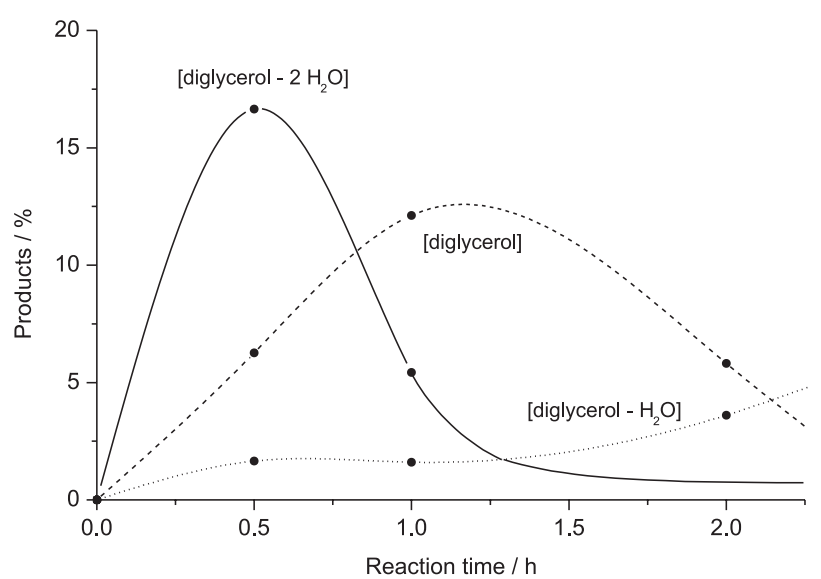

Figure 4. (a) Fractions of the ions of $m / z 167\left([\text { diglycerol }+\mathrm{H}]^{+}\right), 149$ $\left(\left[\text { diglycerol }-\mathrm{H}_{2} \mathrm{O}+\mathrm{H}\right]^{+}\right)$, and $131\left(\left[\text { diglycerol }-2 \mathrm{H}_{2} \mathrm{O}+\mathrm{H}\right]^{+}\right)$as a function of reaction time. Each fraction was calculated as the quotient ratio between the absolute intensity of one of such ions and the sum of the absolute intensities of the whole set of ions.

\section{Conclusions}

The results described herein demonstrated the usefulness of ESI-MS in revealing new and relevant aspects on the acid-catalyzed oligomerization of glycerol. Hence, under the drastic conditions employed herein (acidic medium and heating) a number of oligomers (diglycerol, triglycerol, tetraglycerol, and pentaglycerol) could be detected. In addition, ESI(+)-MS, in conjunction with the data provided by IR and NMR techniques, clearly revealed the presence of secondary products formed by the dehydration of such primary oligomers. These dehydration products are possibly comprised by a mixture of cyclic and unsaturated acyclic compounds (alkenes, aldehydes, and ketones).

\section{Acknowledgments}

The authors are grateful to UFMG, FAPEMIG, CNPq and CAPES for the financial support.

\section{References}

1. Macedo, C. C. S.; Abreu, F. R.; Tavares, A. P.; Alves, M. B.; Zara, L. F.; Rubim, J. C.; Suarez, P. A. Z.; J. Braz. Chem. Soc. 2006, 17, 1291.

2. Domingos, A. K.; Saad, E. B.; Vechiatto, W. W. D.; Wilhelm, H. M.; Ramos, L. P.; J. Braz. Chem. Soc. 2007, 18, 416.

3. Freitas, L.; Perez, V. H.; Santos, J. C.; de Castro, H. F.; J. Braz. Chem. Soc. 2007, 18, 1360.

4. Chaves, E. S.; Saint'Pierre, T. D.; dos Santos, E. J.; Tormen, L.; Bascunan, V. L. A. F.; Curtius, A. J.; J. Braz. Chem. Soc. 2008, 19,856 .
5. Milinsk, M. C.; Matsushita, M.; Visentainer, J. V.; de Oliveira, C. C.; de Souza, N. E.; J. Braz. Chem. Soc. 2008, 19, 1475.

6. Melo, W. C.; dos Santos, A. S.; Santa Anna, L. M. M.; Pereira Jr., N.; J. Braz. Chem. Soc. 2008, 19, 418.

7. Bouaid, A.; Martinez, M.; Aracil, J.; Bioresour. Technol. 2009, 100, 2234.

8. Chen, X. Q.; Liu, C. J.; Wang, J.; Li, Y. P.; Chin. J. Org. Chem. 2009, 29, 128.

9. Guru, M.; Artukoglu, B. D.; Keskin, A.; Koca, A.; Energy Convers. Manage. 2009, 50, 498.

10. Pinto, A. C.; Guarieiro, L. L. N.; Rezende, M. J. C.; Ribeiro, N. M.; Torres, E. A.; Lopes, W. A.; Pereira, P. A. P.; de Andrade, J. B.; J. Braz. Chem. Soc. 2005, 16, 1313.

11. Buhler, W.; Dinjus, E.; Ederer, H. J.; Kruse, A.; Mas, C.; J. Supercrit. Fluid 2002, 22, 37.

12. Stein, Y. S.; Antal, M. J.; Jones, M.; J. Anal. Appl. Pyrolysis 1983, 4, 283.

13. Valliyappan, T.; Bakhshi, N. N.; Dalai, A. K.; Bioresour. Technol. 2008, 99, 4476.

14. Li, M. Y.; Zhou, C. H.; Beltramini, J. N.; Yu, W. H.; Fan, Y. X.; Prog. Chem. 2008, 20, 1474.

15. Garcia, R.; Besson, M.; Gallezot, P.; Appl. Catal., A 1995, 127, 165.

16. Ketchie, W. C.; Murayama, M.; Davis, R. J.; J. Catal. 2007, 250, 264.

17. Villa, A.; Campione, C.; Prati, L.; Catal. Lett. 2007, 115, 133.

18. Barrault, J.; Clacens, J. M.; Pouilloux, Y.; Top. Catal. 2004, 27 , 137.

19. Behr, A.; Eilting, J.; Irawadi, K.; Leschinski, J.; Lindner, F.; Green Chem. 2008, 10, 13.

20. Clacens, J. M.; Pouilloux, Y.; Barrault, J.; Appl. Catal., A 2002, 227, 181.

21. Karinen, R. S.; Krause, A. O. I.; Appl. Catal., A 2006, 306, 128.

22. Klepacova, K.; Mravec, D.; Bajus, M.; Chem. Pap.-Chem. Zvesti 2006, 60, 224.

23. Barrault, J.; Jerome, F.; Pouilloux, Y.; Lipid Technol. 2005, 17, 131.

24. Klepácová, K.; Miravec, D.; Hájeková, E.; Bajus, M.; Petrol. Coal 2003, 45, 54.

25. Zhou, C. H. C.; Beltramini, J. N.; Fan, Y. X.; Lu, G. Q. M.; Chem. Soc. Rev. 2008, 37, 527.

26. Arakawa, R.; Lu, J.; Mizuno, K.; Inoue, H.; Doe, H.; Matsuo, T.; Int. J. Mass Spectrom. 1997, 160, 371.

27. Dalmazio, I.; Almeida, M. O.; Augusti, R.; Alves, T. M. A.; J. Am. Soc. Mass Spectrom. 2007, 18, 679.

28. Dalmázio, I.; de Urzedo, A. P. F. M.; Alves, T. M. A.; Catharino, R. R.; Eberlin, M. N.; Nascentes, C. C.; Augusti, R.; J. Mass Spectrom. 2007, 42, 1273.

29. Dalmazio, I.; Santos, L. S.; Lopes, R. P.; Eberlin, M. N.; Augusti, R.; Environ. Sci. Technol. 2005, 39, 5982. 
30. de Urzedo, A. P. F. M.; Diniz, M. E. R.; Nascentes, C. C.; Catharino, R. R.; Eberlin, M. N.; Augusti, R.; J. Mass Spectrom. 2007, 42, 1319.

31. de Urzedo, A. P. F. M.; Nascentes, C. C.; Diniz, M. E. R.; Catharino, R. R.; Eberlin, M. N.; Augusti, R.; Rapid Commun. Mass Spectrom. 2007, 21, 1893.

32. Florencio, M. H.; Pires, E.; Castro, A. L.; Nunes, M. R.; Borges, C.; Costa, F. M.; Chemosphere 2004, 55, 345.

33. Griep-Raming, J.; Meyer, S.; Bruhn, T.; Metzger, J. O.; Angew. Chem., Int. Ed. 2002, 41, 2738.

34. Hess, T. F.; Renn, T. S.; Watts, R. J.; Paszczynski, A. J.; Analyst 2003, 128, 156.

35. Kotiaho, T.; Eberlin, M. N.; Vainiotalo, P.; Kostiainen, R.; J. Am. Soc. Mass Spectrom. 2000, 11, 526.

36. Madeira, P.; Nunes, M. R.; Borges, C.; Costa, F. M. A.; Florencio, M. H.; Rapid Commun. Mass Spectrom. 2005, 19, 2015.
37. Meyer, S.; Koch, R.; Metzger, J. O.; Angew. Chem., Int. Ed. 2003, 42, 4700 .

38. Moura, F. C. C.; Araujo, M. H.; Dalmazio, I.; Alves, T. M. A.; Santos, L. S.; Eberlin, M. N.; Augusti, R.; Lago, R. M.; Rapid Commun. Mass Spectrom. 2006, 20, 1859.

39. Sabino, A. A.; Machado, A. H. L.; Correia, C. R. D.; Eberlin, M. N.; Angew. Chem., Int. Ed. 2004, 43, 4389.

40. Santos, L. S.; Dalmazio, I.; Eberlin, M. N.; Claeys, M.; Augusti, R.; Rapid Commun. Mass Spectrom. 2006, 20, 2104.

41. Santos, L. S.; Knaack, L.; Metzger, J. O.; Int. J. Mass Spectrom. 2005, 246, 84.

42. Santos, L. S.; Pavam, C. H.; Almeida, W. P.; Coelho, F.; Eberlin, M. N.; Angew. Chem., Int. Ed. 2004, 43, 4330.

Received: February 10, 2009 Web Release Date: September 11, 2009 